Гусарова Марина Александровна

кандидат социологических наук, доцент, доцент кафедры общетеоретических правовых дисциплин Северо-Кавказского филиала Российского

государственного университета правосудия

\section{РОЛЬ ПРАВОСОЗНАНИЯ В ПРАВОВОЙ СИСТЕМЕ ОБЩЕСТВА (НА ПРИМЕРЕ ИНТЕГРАТИВНОГО ПОДХОДА)}

Аннотация:

В фокусе научного интереса автора - правосознание и его роль в правовой системе общества. Анализируя позиции современных зарубежных и отечественных правоведов и философов по проблеме определения места и роли правового сознания в правовой системе и правовой реальности, автор приходит к следующим выводам. Во-первых, в настоящее время в условиях глобализации приобретает особую актуальность интегративный подход к праву, позволяющий систематизировать правовые и внеправовые факторы, обусловливающие формирование правосознания. Во-вторых, факт коммуникации правовой системы, а также диалогичность (диалог социальных субъектов и систем) и относительная автономность его субъектов являются неотъемлемыми условиями развития современной правовой сфреры. В заключение констатируется, что построение правового государства без идеологического и институционального обеспечения названных условий является невозможным.

Ключевые слова:

правосознание, правовая система, социальное пространство, глобализация, правопонимание, коммуникативный подход, диалогическая концепция, интегративный подход.

\section{Gusarova Marina Aleksandrovna}

PhD in Social Science, Associate Professor, General Theoretic Legal Department, North Caucasus branch of Russian University of Justice

\section{THE ROLE OF THE SENSE OF JUSTICE IN THE LEGAL SYSTEM OF THE SOCIETY (BASED ON THE INTEGRATIVE APPROACH)}

The research focuses on the sense of justice and its role in the legal system of the society. Having analyzed the views of modern Russian and international legal scientists and philosophers on the problem of determining the place and role of legal consciousness in the legal system and legal reality, the author comes to the following conclusions. Firstly, an integrative approach to the law is of particular relevance today in the context of globalization. It makes it possible to systematize the legal and non-legal factors contributing to the development of the sense of justice. Secondly, the fact of communication of the legal system, the dialogic nature (the dialogue between social actors and systems) and the relative autonomy of its actors are essential for the development of the modern legal sector. In conclusion, it is stated that it is impossible to construct a rule-of-law state without ideological and institutional provision of the above-mentioned terms.

Keywords: sense of justice, legal system, social space, globalization, legal thinking, communicative approach, dialogical concept, integrative approach.

Проблема объяснения природы социального пространства и правового как его части, в которой коммуникативные и интегративные связи между социальными субъектами построены на искусственных регулятивах как условиях совместного сосуществования, подкрепленных в общественном и индивидуальном правовом сознании естественными (морально-нравственными) основаниями, сама по себе не нова. Она рассматривалась И. Кантом и представителями Марбургской школы (Г. Когеном, Э. Кассирером, Р. Штаммлером). В отечественной дореволюционной философии права данная проблематика нашла отражение в трудах П.И. Новгородцева, И.А. Ильина, Б.А. Кистяковского и др. В современном философском и теоретико-правовом знании исследование взаимодействия правосознания и правовой системы вновь приобретает актуальность в связи с активизировавшимися процессами обмена информацией и усилившейся межкультурной коммуникацией, вызванными глобализацией мирового пространства. Глобализация не могла не затронуть оснований правового пространства и правовых регулятивов, призванных выполнять упорядочивающую функцию во всех сферах общества (экономической, политической, социальной, духовной), что, следовательно, сказалось на изменении правосознания на всех уровнях его развития. Известный отечественный правовед, разработчик научно обоснованной концепции интегративного правопонимания В.В. Ершов справедливо отмечает, что глобализация - это явление не только социальное, экономическое, политическое, но и правовое, поскольку в современном обществе объективным фактом становится тесное взаимодействие принципов и норм международного и внутригосударственного права, образующих правовую систему, в связи с чем актуализируется интегративный подход к пониманию права [1, с. 12-14]. 
Современный бельгийский правовед М. ван Хук, объясняя механизм признания правовых норм на уровне общественного правосознания, считает, что такая «широкая коммуникация, в которой могут принимать участие не только юристы, но и политики, средства массовой информации и большая часть населения, особенно когда обсуждаются важные моральные или политические идеи, есть главное условие для легитимации законов» [2, с. 9]. Отстаивая вслед за Н. Луманом идею системности права, Хук выделяет такие социально значимые характеристики системы права, как нормативность и институционализированная организация правовых ценностей и норм. При этом под нормативностью ученый понимает такое свойство права, которое, будучи внешним для индивида фрактом, не описывает, а определяет реальность или, точнее, межчеловеческое поведение [3, с. 29-31]. Институционализацию права Хук представляет как существующую в двух аспектах - структурном и процедурном и простирающуюся в двух уровнях - правотворчестве и правоприменении [4, с. 35]. Правовая система, согласно мнению Хука, выступает частью социальной системы в целом, которая порождает право. Последнее, как представляется, обусловливает факт непрекращающегося процесса коммуникации правовой системы с остальными социальными системами (религиозными, морально-нравственными, политическими, экономическими и др.), а следовательно, их относительную автономность. Следует согласиться с позицией Хука в том, что «отношения правовых систем с внешним миром представляют собой постоянную коммуникацию, а не одностороннее информирование. Эта коммуникация особенно четко проявляется при толковании закона судами, когда фракты конкретного дела, его специфические обстоятельства, иногда изменившиеся общественные представления и прочие факторы могут основательно повлиять на исход дела» [5, с. 64]. Относительная автономность правовых систем предполагает согласие права с остальными системами на уровне общественного правосознания. В противном случае, как категорично заявляет ученый, «такое право долго не просуществует» [6, с. 71].

Важно отметить, что положительная оценка и признание правовых норм в качестве образца должного поведения, а также синергия правовой системы с остальными социальными системами необходимы не только для достижения функции правопорядка в обществе, но прежде всего для жизнеспособности самой правовой системы. Хук правильно подмечает, что «правовые системы опираются на коммуникацию и нуждаются в коммуникации с внешним миром для того, чтобы производить новые правила» [7, с. 70]. Таким образом, можно сделать вывод, что сам фракт необходимости постоянного изменения правовой реальности вслед за изменяющейся социальной реальностью и ее условиями служит аргументом в пользу внутренней подвижности, трансформации правовой системы. В данном случае интегративный подход к праву в снятом виде включает в себя социологический подход.

Соглашаясь с критической оценкой М. ван Хуком позитивистского похода, подчеркнем, что предпринятая Г. Кельзеном, Г. Хартом, Г.Ф. Шершеневичем и др. попытка «очищения» правовой системы от идеологического влияния других социальных систем, являющаяся по сути признанием абсолютной автономности права как системы, неизбежно исключает возможность влияния разнообразных факторов культурно-исторического, этнокультурного характера. В такой трактовке правовая система будет представлять собой обезличенную совокупность правовых норм и санкций без какой бы то ни было привязки к пространственно-временным особенностям общества. Сам же феномен правовой системы в таком варианте перестает существовать как социокультурный феномен, базирующийся на принципе диалога социальных субъектов и систем. Сторонником схожей научной позиции является Х.Дж. Берман, один из основателей интегральной юриспруденции, предпринявший, на наш взгляд, достаточно успешную попытку объединения трех классических подходов к пониманию права и подчеркнувший тем самым системность и многоуровневость права как социального феномена, включающего в себя все многообразие правовых явлений, в числе которых особое место занимает общественное правосознание [8].

Практически в унисон с упомянутыми выше авторами идею системности права отстаивает современный российский правовед В.В. Ершов. Под правом ученый понимает систему принципов и норм международного и (или) национального права, реализующихся в данном государстве [9, с. 58]. Синтез, интеграция правовых элементов международного и внутригосударственного права, по его мнению, обеспечивают «сбалансированное состояние (гомеостазис), взаимосвязь, целостность и внутреннее единство: непротиворечивость, последовательность, ожидаемость и объективность как правотворческих, так и правореализационных процессов» [10, с. 306-307]. В связи с тем что вопрос о роли и значении правосознания не относился к числу поставленных В.В. Ершовым исследовательских задач, можно предположить, что правосознанию в данной концепции отводится роль связующего звена в правовой системе, осуществляющего коммуникативную и диалогическую функцию как на уровне общественного правосознания, так и посредством профрессионального правового сознания [11]. 
Другой отечественный правовед и фрилософ, разработчик диалогической концепции права (одного из направлений интегративного правопонимания) И.Л. Честнов в своих размышлениях о природе и сущности правовых явлений справедливо подчеркивает, что правовая реальность как часть социальной реальности представляет собой «социальный конструкт», «результат деятельности (как фрактической, «поведенческой», так и мыслительной, ментальной) человека...» [12, с. 45]. При этом право как многоаспектный феномен, по мнению ученого, включает «нормы, правосознание, правопорядок, в котором реализуются как нормы, так и правосознание. Сам человек (как абстрактная сущность и одновременно ее конкретное воплощение в эмпирически данном человеке) присутствует и в нормах права, и в правосознании, и в правопорядке» [13, с. 50-51]. В процессе осознания правовых норм социальными субъектами происходит интериоризация внешних, безличных правовых ценностей и норм во внутренне значимые ценности, мотивации и установки на правовое поведение. Таким образом, по словам И.Л. Честнова, феномен правогенеза носит диалогический по своей сути характер, в процессе осуществления которого социально-правовая реальность «конструируется», «объективируется», а ее элементы подвергаются тщательному селективному отбору правовым сознанием. В результате такой деятельности достигается преодоление антиномичности элементов правового бытия посредством диалога общественно значимого и индивидуально значимого, идеальных правовых конструкций и реальных правовых институтов, обезличенных и конкретных прав и обязанностей гражданина.

Отечественный философ и правовед А.В. Поляков, разработчик френоменолого-коммуникативного подхода, также не оставил без внимания признак системности права, которое он определяет как «тотальную и синергийную интерсубъективную реальность... включающую в себя как нормы, так и правоотношения, как ценности, так и правосознание, как правовые тексты, так и деятельность по их интерпретации и претворению в жизнь» [14, с. 7].

Современный правовед С.И. Архипов справедливо подчеркивает, что коммуникация субъектов внутри правовой системы, несмотря на некоторые схожие признаки с формами коммуникации внутри других систем (религиозных, политических, моральных и иных), имеет специфические особенности, обусловленные характером и сущностью права как феномена. Среди характеристик данного феномена он выделяет следующие. Во-первых, исходным пунктом правовой коммуникации является субъект права. Во-вторых, каждый правовой субъект должен признавать автономную волю и интересы остальных субъектов. В-третьих, правовая коммуникация имеет корпоративную природу [15]. Соглашаясь с изложенными признаками, заметим, что они взаимодополняют друг друга и не могут существовать сами по себе. Специально заметим, что представленная выше логика коммуникативных, диалогических связей между правовыми субъектами внутри правовой системы может иметь место только в случае сформированного на этих принципах правосознания, о чем еще на рубеже XIX-XX вв. писали великие отечественные философы и правоведы, сторонники юснатуралистического и социологического подходов к определению права и правосознания. Однако в современных условиях данная идея, по нашему мнению, приобретает особую актуальность, поскольку ни одно цивилизованное государство, заявившее о себе на уровне конституционного закрепления как демократическое и правовое, не сможет достичь поставленных правовых «высот» без диалога и коммуникации. Сам же принцип демократизма в современном глобализирующемся социальном пространстве, по словам В.С. Степина, «обеспечивает эффективное управление сложными системами, поскольку предполагает многообразные обратные связи, корректирующие управленческие решения» [16, с. 17].

Подводя итоги сказанному выше, отметим, что, во-первых, устройство современной правовой системы должно предусматривать идеологическую и институциональную возможность свободного диалога социальных субъектов как автономных (но при этом функционирующих в рамках системных связей) единиц правового пространства; во-вторых, правовая система должна находиться в подвижном состоянии поиска компромиссов, баланса между социальной инженерией и культурной традицией. Тогда и только тогда она сможет эфффективно выполнять свои главные функции - достижение необходимого уровня социального порядка, институциональное правовое обеспечение интеракций и коммуникаций в обществе, согласование общественных и индивидуальных интересов на уровне, адекватном состоянию современной цивилизации.

\section{Ссылки:}

1. Ершов В.В. Правовое и индивидуальное регулирование общественных отношений : монография. М., 2018. 627 с.

2. Хук М. ван. Право как коммуникация : пер. с англ. СПб., 2012. 288 с.

3. Там же. С. 29-31.

4. Там же. С. 35.

5. Там же. С. 64.

6. Там же. С. 71.

7. Там же. С. 70. 
8. Berman H.J. American and Soviet Perspectives on Human Rights // Worldview. 1979. November. P. 15-21.

9. Ершов В.В. Указ. соч. С. 58.

10. Там же. С. 306-307.

11. Гусарова М.А. Функции правосознания как социокультурного феномена // Aspectus. 2016. № 4. C. 95-98.

12. Честнов И.Л. Конструирование социальной и правовой реальности: к формированию диалогической онтологии права // Платон. 2012. № 1. С. 45-51.

13. Там же. С. $50-51$.

14. Поляков А.В. Общая теория права: проблемы интерпретации в контексте коммуникативного подхода : учебник. 2-е изд., испр. и доп. М., 2016. 832 с.

15. Архипов С.И. Понятие правовой коммуникации // Российский юридический журнал. 2008. № 6. С. 7-17.

16. Степин В.С. Глобализация и диалог культур: проблема ценностей // Век глобализации. 2011. № 2. С. 8-17.

\section{References:}

Arkhipov, SI 2008, 'The Concept of Legal Communication', Rossiyskiy yuridicheskiy zhurnal, no. 6, pp. 7-17, (in Russian). Berman, HJ 1979, 'American and Soviet Perspectives on Human Rights', Worldview, November, pp. 15-21.

Chestnov, IL 2012, Construction of Social and Legal Reality: Concerning the Development of the Dialogical Ontology of Law', Platon, no. 1, pp. 45-51, (in Russian).

Ershov, VV 2018, Legal and Individual Regulation of Social Relations, monograph, Moscow, 627 p., (in Russian).

Gusarova, MA 2016, 'Functions of Legal Consciousness as a Social and Cultural Phenomenon', Aspectus, no. 4, pp. 95-98, (in Russian).

Hoecke, M van 2012, Law as Communication, St. Petersburg, 288 p., (in Russian)

Polyakov, AV 2016, General Theory of Law: the Problems of Interpretation in the Context of a Communicative Approach, textbook, 2nd ed., Moscow, 832 p., (in Russian).

Stepin, VS 2011, 'Globalization and Dialogue of Cultures: the Problem of Values', Vek globalizatsii, no. 2, pp. 8-17, (in Russian). 